\title{
LA POESÍA PEDERÁSTICA EN HORACIO: EL EPODO XI ${ }^{1}$
}

The first part of this paper offers an introductory discussion of all pederastic allusions found in Horace. The second part is a literary commentary of Horace's Epode XI. This poem begins with Horace informing Pettius that love is interfering with his writing of poetry (1-6). In the verses that follow, Horace gives an account of his painful involvement with Inachia (7-22). Now, howerer, he is in love with Lyciscus, and only love for another will free him from the affair (23-28). The poet has here made use of themes current in Hellenistic erotic poetry, specially in epigrams. Horace's Epode XI is an elegant piece of writing, but there is little real life in it.

\section{Pederastia en la poesía latina}

El epodo objeto de nuestro estudio se inscribe dentro del amplio marco de temas y formas constituido por la llamada poesía pederástica, poesía homosexual o mousa paidiké.

La inspiración lírica de Horacio bebe fundamentalmente de tres fuentes bien definidas: de la poesía griega antigua (Arquíloco, Solón, Hiponacte, Alceo, Safo, Anacreonte, Íbico, Píndaro, Teognis); de la poesía helenística y alejandrina (Teócrito y la Antología Palatina); y de su análogo romano, el neoterismo. Pues bien, en estas tres etapas poéticas ocupa un lugar importante el tema del amor pederástico ${ }^{2}$.

A finales del siglo II a. C. y a principios del I a. C. el epigrama erótico helenístico, de amor homosexual, había penetrado ya en las letras latinas de la mano de Porcio Licinio, Q. Lutacio Cátulo y Valerio Edituo. En efecto, a Porcio Licinio le debemos el más antiguo epigrama latino de tema pederástico,

1 Deseamos expresar nuestro agradecimiento al Dr. D. Gabriel Laguna Mariscal por las correcciones y sugerencias efectuadas al artículo.

2 Cf. F. Buffière, Eros adolescent. La pédérastie dans la Grèce antique, Paris, 1980, pp. 239-266 para la poesía griega antigua de tema homosexual; pp. 267-291 para la poesía alejandrina de este tema; pp. 293-324 para los autores de la Antologia Palatina que cultivan esta modalidad poética, especialmente en el libro XII. 
conservado por Aulo Gelio (XIX 9,13). También de Lutacio Cátulo ${ }^{3}$ conocemos dos epigramas de tema similar: uno, donde proclama su amor por Teotimo; y otro, donde celebra la belleza del actor Roscio. Valerio Edituo también dedica un poema de amor a un tal Fileros, posiblemente su joven esclavo ${ }^{4}$. Posteriormente, los poetas neotéricos, cuyo más conspicuo representante era Catulo, compusieron igualmente diversos epigramas eróticos y amorosos donde elogiaban la hermosura y juventud de algún esclavo o mancebo y celebraban el amor que el propio poeta sentía por tal muchacho y las experiencias amorosas que con él había mantenido, siempre dentro de esa línea intimista que anunciaba ya el próximo nacimiento de la elegía como género literario autónomo. Éste es el caso de los poemas que Catulo dirige a Juvencio ${ }^{5}$.

En este recorrido por la poesía pederástica en Roma, no debemos olvidar a Virgilio. En la égloga II canta el amor no correspondido del pastor Coridón por el efebo Alexis, con amplias reminiscencias alejandrinas, especialmente del Cíclope de Teócrito.

Entre los autores propiamente elegíacos que cultivan la poesía de tema pederástico, sobresale Tibulo ${ }^{6}$ con las famosas composiciones 4,8 y 9 de su primer libro, las que conforman el llamado ciclo de Márato y que tanto deben a esa tradición griega y latina, sobre todo a Catulo y a su célebre ciclo de Juvencio ${ }^{7}$.

Pues bien, Horacio contribuye a esta tradición con tres composiciones: el epodo XI y las odas IV 1 y IV 10. En estas composiciones el poeta, casi transformado en elegíaco, si no fuera por el metro utilizado, recurre a toda una serie de motivos y tópicos amatorios trillados en la poesía elegíaca. Estudiaremos en el presente trabajo el epodo XI, pues de las otras dos odas ya nos hemos ocupado en otra ocasión ${ }^{8}$. Antes consignaremos algunas alusiones espigadas en la obra poética del Venusino, que manifiestan el gusto del poeta

${ }^{3}$ Cf. G. Laguna Mariscal, «La aportación de Q. Lutacio Catulo a la lírica romana (epigr. 2)", CFCLat. 5, 1993, pp. 55-63.

${ }^{4}$ Cf. P. Grimal, Le lyrisme à Rome, Paris, 1978, p. 79 ss.

${ }^{5}$ Cf. Catull. $15 ; 16 ; 21 ; 23 ; 24 ; 48 ; 81$ y 99. Cf. G. Williams, Tradition and Originality in Roman Poetry, Oxford, 1985 (= 1968), pp. 550-556; J. Griffin, Latin Poets and Roman Life, Chapel Hill, 1986, pp. 24-25.

${ }^{6}$ De los elegíacos (Comelio Galo, Propercio, Tibulo y Ovidio) sólo Tibulo tiene un ciclo de poesía pederasta. Propercio no cultiva el género y Ovidio se expresó explícitamente en contra de las relaciones homoeróticas (Ars II 683-684), aun cuando encontramos una alusión muy leve en $A m$. I 1, 20.

${ }^{7}$ Cf. J. L. Arcaz Pozo, Tibulo: Elegias, Introd., trad. y notas de..., Madrid, 1994. En pp. 48 ss. se ofrece abundante bibliografía moderna.

8 Cf. M. Mañas Núñez, «Horacio y la poesía pederasta: tradición y originalidad (Odas 4,1 y 4,10 )», en R. Cortés Tovar y J. C. Fernández Corte (eds.), Bimilenario de Horacio, Salamanca, 1994, pp. 323-330. 
por el tema de la pederastia. En ellas aún no hallamos ese verdadero lirismo subjetivo donde Horacio nos habla en primera persona de sus goces y penas de amor, sino que estas alusiones reflejan sólo los meros deseos sexuales, las diversiones y placeres físicos a los que Horacio y sus amigos aspiran.

\section{Alusiones PEDERÁSTICAS EN LA POESÍA hORACIANA}

En el cancionero horaciano encontramos numerosas alusiones y referencias a relaciones homosexuales entre hombres dentro de composiciones cuyo tema principal no consiste en el canto de los amores entre un amante y su amado. Se trata, en efecto, de citas aisladas, que sirven para ilustrar diversos cuadros o circunstancias, tomadas a veces de la propia realidad que rodea al poeta y a los destinatarios del poema en cuestión, de la mitología o incluso, otras veces, sacadas de la misma imaginación del escritor.

En el Epodo XIV el poeta se excusa ante Mecenas por la demora en la finalización del libro de los Epodos, respondiéndole que su inactividad literaria se debe a que se halla enamorado de Frine y ese amor no le permite escribir. Para justificar su pasión amorosa y la consiguiente impotencia literaria, Horacio responde a su protector que también Anacreonte, poeta como él, se enamoró de Batilo de Samos, utilizando así una relación pederástica para ejemplificar su propia actitud:

non aliter Samio dicunt arsisse Bathyllo Anacreonta Teium,

qui persaepe caua testudine fleuit amorem non elaboratum ad pedem.

... me libertina neque uno contenta Phryne macerat (9-12 y $15-16)^{9}$.

Igualmente, en la oda I 4, donde Horacio constata la universalidad de la muerte y el fin, con ella, de los placeres, advierte en seguida a su amigo L. Sestio que una vez que la Noche, los Manes y la morada de Plutón le apremien

nec tenerum Lycidan mirabere, quo calet iuuentus nunc omnis et mox uirgines tepebunt (19-20).

Es, prácticamente, una admonición al goce del presente, tan querido de Horacio ${ }^{10}, y$, en este caso, al goce de las ternuras de su amado Lícidas.

\footnotetext{
9 Para los textos horacianos citados seguimos la edición de D. R. Shackleton Bailey, $Q$. Horati Flacci: Opera, Stutgardiae, 1985.

10 Sobre el Carpe diem horaciano, cf. H. Bardon «Carpe diem», Revue des Études Anciennes 46, 1944, pp. 345-355; P. Gilbert, «Horace et l'Egipte. Aux sources du Carpe diem», Latomus 5, 1946, pp. 61-74; A. Traina, «Semantica del carpe diem», RFIC 101, 1973, pp. 5-21.
} 
En otra oda (I 29), dirigida a Iccio, un filósofo estoico declarado que decide enrolarse en una expedición militar a Oriente con el fin de enriquecerse, Horacio reprende con ironía al destinatario de la poesía. Cuando regrese rico de sus andanzas militares, nos dice el poeta, traerá seguramente algún bello mancebo que le sirva como copero:

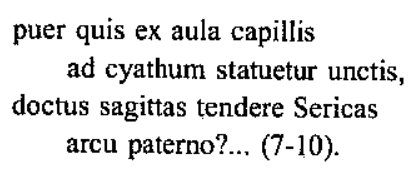

Rápidamente nos viene a la mente la imagen de Júpiter raptando al mancebo Ganimedes, quiẹn, además de ser copero del dios, era también el joven objeto de sus amores. No sería descabellado pensar que Iccio se trajera algún bello efebo para sus juegos amorosos.

En otra ocasión, en una poesía claramente programática en la que el Venusino expresa sus gustos literarios (oda I 32), invoca a la lira eolia para que le inspire un poema escrito en latín, pero según las formas y temas usados por Alceo. Así, nos recuerda cómo el de Mitilene cantó a Líber, a las Musas, a Venus, a Cupido

et Lycum nigris oculis nigroque crine decorum (11-12).

No es raro, pues, que Horacio imite en sus poesías líricas todos estos temas, a saber, el tema del vino y de la fiesta simposiaca, del encuentro erótico-amoroso o el tema de la propia reflexión sobre la poesía, incluido el del amor por los jóvenes muchachos.

Hay ocasiones en que la relación de amistad " entre dos amigos puede entenderse en un sentido más íntimo, rozando incluso las lindes del amor homosexual. Éste es el caso de la oda I 36, poesía de bienvenida o prosphonetikón a su amigo Númida, que regresaba de España. Horacio le invita a un banquete para celebrar su vuelta. En este convite reencuentra a sus antiguos amigos. Entonces Númida, en la euforia del regreso y de la presencia de sus amigos, los saluda efusivamente, besándolos a todos, pero sobre todo y muy especialmente a Lamias:

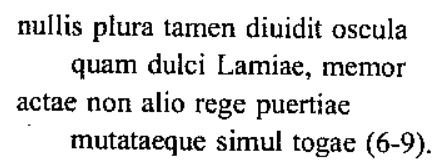

"El de la amistad es uno de los temas más relevantes en las Odas de Horacio, cf. H. Storch, «Freundschaft, Freundlichkeit und Liebe in den Oden des Horaz», Der altsprachliche Unterricht 12, 5, 1970, pp. 5-26. 
Una oda en donde se nos muestra una evidente relación de amor homosexual es en la Il 9. Aquí nos aparece Valgio Rufo, amigo de Horacio y también poeta, gramâtico y traductor de la Rétorica de Apolodoro, profundamente afligido por la muerte de su esclavo y, seguramente, amado Mistes:

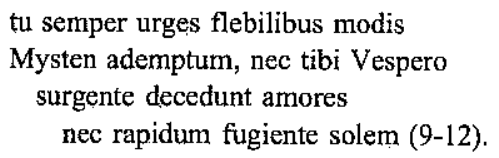

Parece claro que el término amores va indicando tanto el sentimíento de amistad y afecto que Valgio sentía por Mistes, como el amor que les unió mientras la muerte no se interpuso entre ambos. En este contexto, Horacio le invita a cambiar el tema lúgubre y doloroso de su poesía y a cantar, más bien, los recientes triunfos de Augusto.

Puede ocurrir, igualmente, que en una misma composición se mezclen el amor heterosexual y el homosexual. Es el caso de la oda III 20, donde se desarrolla la disputa entre Pirro y una mujer no nombrada por conseguir las delicias del mancebo Nearco. El muchacho es un hermoso joven, cuya excelsa belleza queda demostrada por la comparación que de él se hace con los personajes mitológicos Nireo y Ganimedes (vv. 15-16). La relación amorosa a tres bandas, Pirro-Nearco y Nearco-mujer innominada, queda caracterizada estilísticamente por el juego creado por el poeta entre el plano metafórico y el real, presentándonos a Pirro como un cazador que roba los cachorros $(=$ Nearco) a una leona $(=$ mujer innominada). El amor es ahora visto como una lucha (grande certamen, v. 7) entre los dos rivales que aspiran a conquistar las lindezas del efebo.

En Catulo veíamos, dentro de las relaciones amorosas homosexuales, cómo sus rivales le querían arrebatar a su amado Juvencio (Catull. 15 y 21, dirigidas contra Aurelio). Dentro de las relaciones amorosas heterosexuales, el foedus amoris entre Catulo y Lesbia también se ve amenazado por la presencia de rivales (cf. poema 91, donde Gelio, amigo de Catulo, le traiciona y se convierte en su rival respecto al amor por Lesbia). También es normal en los elegíacos la existencia de algún hombre que rivaliza con el poeta por el amor de una mujer ${ }^{12}$. Horacio, en este caso, ha seguido la tradición, pero ha innovado considerablemente presentando la rivalidad en términos diferentes. En efecto, en esta oda III 20 son dos personas de sexo contrario (Pirro y la mujer) quienes se afanan por conseguir el amor de un tercero (Nearco), cuando lo habitual era presentar la rivalidad mediante la lucha entre dos personas del mismo sexo.

12 Propercio, por ejemplo, se encuentra con diversos rivales (Baso, Galo, etc.) en sus relaciones con Cintia, cf. I 4; 5; 8 . Asimismo, Tibulo, en el plano de la poesía pederástica, ve cómo su amado Márato es seducido por un diues amator (I 9). En otro plano, Ovidio (Am. I 4) ve al marido como un rival en sus amores con Corina. 
En las Sátiras y en las Epistolas encontramos otras referencias aisladas que evidencian la actitud y gustos bisexuales de Horacio, indiferente tanto por los muchachos como por las muchachas. Así, cuando el estoico Damasipo expone las circunstancias que le han llevado a concluir que el Venusino se encuentra afectado por una enfermedad anímica, concretamente la locura, el filósofo hace referencia, con muestras de desaprobación, a los mille puellarum, puerorum mille furores (Serm. II 3,325) alabados en su poesía.

Para Horacio, es mero asunto de gustos el que un hombre prefiera el amor masculino o femenino:

hic nuptarum insanit amoribus, hic puerorum (Serm. 1 4,27).

En cuanto al ámbito personal de Horacio, alguna vez se nota una ligera preferencia por el amor femenino, aun cuando en Serm. I 2,116-119 admite el amor masculino y el femenino como objetos igualmente naturales del deseo sexual:

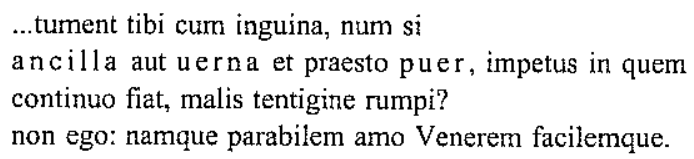

Las líneas que siguen sólo conciernen al amor femenino.

Igualmente, dentro de los consejos que Horacio prodiga a su amigo Lollio, encontramos las diferentes actitudes que pueden existir respecto a un esclavo masculino o femenino:

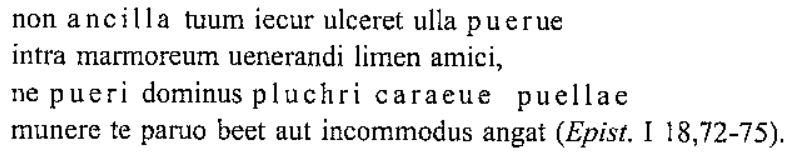

En fin, todas estas referencias aisladas que hemos extraído de las distintas obras de Horacio no componen un corpus orgánico y sistemático en el que podamos decir que la poesía pederástica sea un tema preferido del Venusino. Son sólo unos cuantos versos tomados de su producción poética, donde, al menos, queda de manifiesto que a un romano se le puede desatar la libido tanto por un bello muchacho como por una hermosa doncella, sin que por ello resultara vergonzoso o inmoral en la sociedad romana del momento ${ }^{13}$.

13 Cf. Catull. 61,126-145, donde presenta al concubinus, compañero habitual de los jóvenes casaderos antes del matrimonio, como una institución establecida; véase también Verg., $E c l$. 2, donde se cantan los amores de Coridón por Alexis. Cf. P. Grimal, L'amour à Rome, Paris, 1963, pp. 119-124. 


\section{El AMOR DE HoRACIO POR LiCISCO: El EPODO XI}

El poema objeto de nuestro estudio constituye por su extensión, temática y tópicos amatorios que despliega una auténtica elegía. Se trata, en efecto, de un poema no muy extenso (veintiocho versos), que desarrolla el tema del amor del poeta por un muchacho (Licisco), con evocaciones de otra antigua pasión por una mujer llamada Inaquia. Para ello, Horacio se sirve del código de descripción típico de la poesía erótico-amatoria latina. Sólo una circunstancia nos impide calificar esta composición literaria como una elegía: la versificación yámbica empleada ${ }^{14}$.

Veamos el texto:

Petti, nihil me, sicut antea, iuuat scribere uersiculos amore percussum graui, amore, qui me praeter omnis expetit mollibus in pueris aut in puellis urere.

hic tertius December ex quo destiti Inachia furere siluis honorem decutit.

heu me per urbem (nam pudet tanti mali) fabula quanta fui! conuiuiorum et paenitet

in quis amantem languor et silentium arguit et latere petitus imo spiritus.

'contrane lucrum nil ualere candidum pauperis ingenium?' querebar applorans tibi,

simul calentis inverecundus deus fervidiore mero arcana promorat loco.

'quod si meis inaestuet praecordiis libera bilis, adhuc ingrata uentis diuidam

fomenta vulnus nil malum leuantia; desinet imparibus certare summotus pudor.'

ubi haec seuerus te palam laudaueram, iussus abire domum ferebar incerto pede

ad non amicos, heu, mihi postis et, heu, limina dura, quibus lumbos et infregi latus.

nunc gloriantis quamlibet mulierculam uincere mollitie amor Lycisci me tenet, unde expedire non amicorum queant libera consilia nec contumeliae graues, sed alius ardor aut puellae candidae aut teretis pueri longam renodantis comam.

14 La idea ya fue expresada por F. Leo, De Horatio et Archilocho, Göttingen, 1900, p. 10: «Est plane elegia iambis concepta» (citado por E. Fraenkel, Horace, Oxford, 1957, p. $67 \mathrm{y} \mathrm{n.1)}$. 
La composición inaugura la que, atendiendo al metro utilizado, se considera segunda parte del libro de los Epodos. Después de la primera, caracterizada por la alternancia de trímetros y dímetros yámbicos, en esta segunda parte afloran nuevas maneras poéticas, menos epódicas y más próximas a la elegía ${ }^{15}$.

\section{a) Estructura}

La estructura del epodo se puede definir como tripartita, con una parte central (vv, 7-22), que contiene el recuerdo de las antiguas desventuras amorosas del poeta con Inaquia, inserta en medio de dos secciones iguales, de seis versos cada una, en las que se presenta el amor por Licisco en el presente. Esta estructura la podemos reflejar así:

I. 1-6: Amor en el presente.

a) 1-4: Profundo amor: falta de inspiración; pasión amorosa por muchachos y muchachas.

b) 5-6: Recuerdo del amor por Inaquia.

II. 7-22: Amor en el pasado: Schetliasmós. Lamento por el amor no correspondido.

a) 7-10: Vergüenza del poeta.

b) 11-18: Diues amator/ pauper Horatius.

c) 19-22: Exclusus amator.

III. 23-28: Amor en el presente.

a) 23-24: Amor presente por Licisco.

b) 25-28: Remedium amoris: alius ardor por alguna muchacha o muchacho.

\section{b) Interpretación}

El epodo constituye una atormentada confesión de Horacio a su amigo y confidente Petio. El poeta se siente gravemente turbado por una pasión que no le deja vivir; una pasión que no entiende de distinciones sexuales y que le incita a desear indistintamente a muchachos y muchachas; una pasión amorosa que no le permite ni siquiera escribir. El causante de este desasosiego anímico y físico que padece Horacio es un mancebo llamado Licisco.

En efecto, el tópico del poeta enamorado que no puede escribir es conocido ya desde tiempos de Arquíloco de Paros:

15 Cf. E. Romano, Q. Orazio Flacco, Le opere. I. Le Odi. Il carmen secolare. Gli Epodi. Tomo secondo. Commento di..., Roma, 1991, pp. 987-988, ad Hor., Epod. XI. 


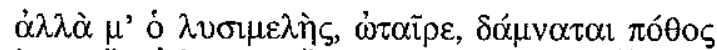

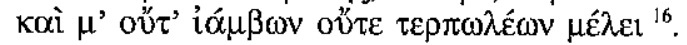

El ambiente en ambos textos es muy parecido: también Arquíloco toma como confidente a un amigo suyo, para desvelarle la pasión interior que le domina y que ha apagado su llama poética. Pero, en realidad, cuando más relevancia adquiere este motivo literario es en época helenística. En efecto, en varios epigramas de la Antología Palatina el amor aparece como una emoción que seca la inspiración poética. El amor despoja al poeta de su arte, le roba la inspiración y es uno de los tormentos que más afecta a la mente de los poetas de esta colección ${ }^{17}$. Volvemos a encontrar el motivo, ya dentro de la literatura latina, en la égloga $\mathrm{X}$ de Virgilio, cuando Cornelio Galo ${ }^{18}$ narra sus desgraciados amores con Licóride. El poeta elegiaco, en medio de los lamentos que dirige a amigos y dioses por la infidelidad de la amada, llega a decir que

iam neque Hamadryades rursus nec carmina nobis

ipsa placent (ecl. X, 62-63).

$\mathrm{Y}$, de hecho, debía de ser un motivo del gusto de Horacio, pues lo vuelve a utilizar en el epodo XIV, cuando expresa el profundo y borrascoso amor que siente por Frine y la impotencia que experimenta para seguir escribiendo y acabar los yambos que tenía comenzados:

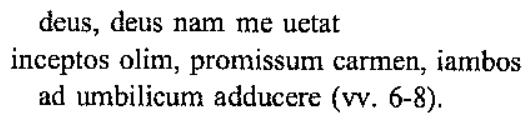

En realidad, el tópico usado por Horacio supone la inversión del motivo típicamente elegíaco de la amada como fuente de inspiración del poeta ${ }^{19}$. Este

16 Archil., frs. 196 y $215 \mathrm{~W}$.

17 Cf. Posidipo, A. P. XII 98; cf. XII 99 y 100; Meleagro, Ibid., XII 101.

18 Tradicionalmente se considera a $\mathrm{C}$. Galo el poeta iniciador del género elegíaco en la literatura latina. En cambio, la crítica actual está de acuerdo en que el creador de la elegía amorosa latina es Catulo, con su poema 68. Galo vivió un loco amor por Licóride, pseudónimo poético de Volumnia Citérida, una mima a la que dedicó cuatro libros de elegías. Durante siglos sólo poseíamos un pentámetro suyo, pero recientemente se ha descubierto un papiro en Egipto que contiene una decena de sus versos. La editio princeps es de 1979, cf. R. D. Anderson - P. J. Parsons - R. G. M. Nisbet, «Elegiacs by Gallus from Quasr Ibrîm», JRS 69, 1979, pp. 125-155. Hablan de Galo los grandes elegiacos posteriores: Prop. II 34b, 91-92; Ov., Ars III, 334; Rem. 765. Quintiliano X 1,93 lo considera durior que los elegiacos que le siguieron. Cf. S. Mazzarino, «Contributo alla lettura del nuevo Gallus, JRS 1979,125 ss. e la storia de la mima Lycoris», $H l k 20-21,1980-1981$, pp. 3-26; L. Nicastri, Cornelio Gallo e l'elegia ellenistico-romana. Studio dei nuovi frammenti, Napoli, 1984; X. Ballester, «Galo: los inicios literarios», CFC 23, 1989, pp. 117-124.

19 Cf. Prop. II 1, 1-6; II 30, 40; III 24, 3-8; Ov., Am. III 12, 16; Tris. IV 10, 59; Mart. VIII 73, 5-6 y XII 4, 5; véase J. F. Miller, «Disclaiming Divine Inspiration: A Programmatic Pattern), Wien. Stud. 99, 1986, pp. 151-156. 
tópico aparece cuando el poeta se siente feliz y correspondido en su amor. Sin embargo, cuando se siente turbado, bien por la infidelidad o porque los sentimientos no son mutuos, observamos la inversión del motivo. Esto es lo que le ocurre a Horacio: está enamorado de Licisco, pero dada la forma como el poeta nos la presenta, adivinamos que se trata de una pasión insana. De ahí la inversión del tópico: ya no supone inspiración, sino anulación de la misma.

Que el amor que siente Horacio por Licisco es nocivo, nos lo indican diversos elementos. En efecto, la propia juntura amore percussum graui (v.2) nos manifiesta que esa pasión es pesada, profunda, malsana y peligrosa. Por ello, el poeta ha escogido el adjetivo grauis, para dar al amor sentido una connotación negativa ${ }^{20}$.

Además, esa connotación negativa y perniciosa que el Venusino confiere a sus sentimientos se halla enfatizada por la repetición anafórica amore...amore (vv. 2-3) y por el uso del verbo expetit (v. 3), propio de la militia amoris ('atacar'). Se trata de un deseo irreflenable, irracional, que escapa de su propio control y le obliga a amar ardorosamente a «tiernos muchachos y muchachas» (v. 4). En este verso 4 ...in pueris aut in puellis urere $\mathrm{y}$ en los versos 27-28

...alius ardor aut puellae candidae aut teretis pueri...

algunos estudiosos han encontrado pruebas irrefutables que demuestran la bisexualidad de Horacio ${ }^{21}$. Pero, en realidad, lo que ocurre es que el poeta está caracterizando su pasión amorosa con tópicos muy conocidos en la elegía 22 . Se trata, por ejemplo, del motivo del amor como una herida, uulnus amoris (amore percussum graui, v. 2) y del tópico del amor como una llama que consume las entrañas del amante, flamma amoris (urere, v. 4) ${ }^{23}$.

20 Si sólo hubiese querido reflejar la intensidad del mismo, habría escrito ingenti percussus amore, como hace Virgilio cuando alude a la pasión que siente por las musas (Georg. I 476), o magno...percussus amore, empleado por el mantuano para resaltar las enormes ganas de gloria que tenía Euríalo (Aen. IX 197); cf. también Ennio, Medea exul 9 Valhen: Medea animo aegro amore saeuo saucia y Virgilio, Aen. IV 1: At regina graul iamdudum saucia cura.

2! Cf. S. Lilja, Homosexuality in Republican and Augustan Rome, Helsinki, 1983, pp. 70-74.

22 En efecto, nos parece una expresión polar convencional (no indicio de bisexualidad), comparable a Hor., Serm. I 2, 117 y Ov., Am. I 1, 20.

${ }_{23}$ Para el motivo del uulnus amoris, cf. R. Pichon, De sermone amatorio apud latinos elegiarum scriptores, Paris, 1902 (reimpr. Hildesheim, 1966), p. 302 s.v. vulnera y J. C. Mckeown, Ovid: Amores. Text, Prolegomena and Commentary, vol. II, A Commentary on book one, Leeds, 1989, p. 48 ad Ov., Am. I 2, 29-30. Sobre la metáfora de la flamma amoris, cf. V. Cristóbal López, Virgilio y la temática bucólica en la tradición clásica, Madrid, 1980, pp. 338-346 y G. Laguna, «Dos imágenes matrimoniales en el episodio de Dafne y Apolo (Ov., Met. I, 452-567): sex crines y las teas de la flamma amoris», Anuario de Estudios Filológicos 12, 1989, pp. 133-143. 
La primera parte que hemos establecido en la estructura del epodo concluye con dos versos que consideramos de transición y cuya función parece ser doble: situar cronológicamente el momento en que Horacio escribe el epodo y conectar el amor presente por Licisco con sus vivencias pasadas con Inaquia. En cuanto a su primer cometido, se nos dice que han pasado dos años desde que dejó de amar a Inaquia. Ello no nos ayuda a conocer la fecha de composición del epodo, pero, al menos, sí nos lleva a descartar que sea uno de los más antiguos, ya que de ese dato cronológico se puede deducir que la composición es por lo menos dos años posterior al epodo XII, en el que una mujer vieja rechazada por Horacio se queja del escaso vigor de aquél y le echa en cara el hecho de que con Inaquia se comporte de manera más efusiva:

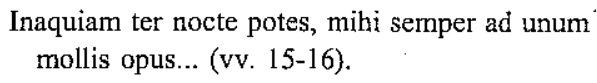

En cuanto a la segunda función de estos dos versos (5-6), creemos que sirven para conectar las ideas expuestas al principio con el resto del poema. Estos versos de transición sirven para dejar claro que hace ya dos años que el poeta dejó de amar a Inaquia. Pero, al igual que en los versos iniciales, para expresar una idea tan simple (res) se sirve de un léxico (uerba) tipificado y cargado de evocaciones y connotaciones fácilmente discernibles. En efecto, el sintagma sujeto Hic tertius December, que por sinécdoque indica «el tercer año» ${ }^{24}$, lleva un verbo acompañado de unos complementos que claramente evocan a Virgilio, Georg. II 404: frigidus et siluis Aquilo decussit honorem, una imagen que, según Servio, está tomada de Varrón Atacino ${ }^{25}$ y que, pensamos, podría ser también el modelo de Horacio. Pero es que, además, el poeta, al expresar el amor que tuvo antaño por Inaquia, utiliza el verbo furere (v. 6): se trata, en efecto, de otro conocido tópico, no sólo en la elegía, sino en toda la poesía latina, el del furor amoris, el amor caracterizado como una enfermedad mental, como una locura ${ }^{26}$.

Pues bien, a partir del verso 7 el poeta se olvida momentáneamente de su presente y rememora el pasado, recordando las desgracias y sufrimientos que le acarreó su antigua relación con Inaquia, siempre dentro de esa concepción epicúrea y lucreciana que ve en el amor una fuente continua de perturbación

\footnotetext{
${ }^{24}$ Como en Epist. I 20,27: quater undenos...impleuisse decembres.

25 Cf. Seruil Grammatici: qui feruntur in Vergilii Bucolica et Georgica commentarii, Recensuit G. Thilo, Hildesheim, 1986 (=Leipzig, 1887), p. 255: Varronis hic uersus est.

${ }^{26}$ Cf. Lucr. IV 1069 y 1117; Catull. 15,14; 50,11; 64,54,94,124; 68, 129; Virg., Ecl. II 1 o X 37 ss., como uno de los atributos de la poesía y existencia de Galo; Prop. I 4, 11-12; 5,$3 ; 9,33-34$; Il 12, 3-4, etc. En el libro de S. Alfonso et al., Il poeta elegiaco e il viaggio d'amore, Bari, 1990, hay un capítulo de I. Mazzini sobre el tema: «Il folle d'amore», pp. 39-83; cf. la reseña de G. Laguna Mariscal en EMERITA 61, 1993, pp. 220-221.
} 
que anula ese ideal de ataraxia (ausencia de turbación en el alma) y aponía (ausencia de dolor corporal) al que aspiraba nuestro poeta.

En efecto, es famoso el final del libro IV del De rerum natura lucreciano (vv. 1058-1191), donde se hace una condena sistemática de la pasión amorosa como perturbación que ataca la serenidad y el equilibrio físico y psíquico. Esa misma condena, aunque quizás más en clave de vergüenza y conmiseración de sí mismo, la podemos observar en la segunda parte del epodo horaciano. El Venusino recuerda, como quien no quisiera volver a pasar por los tormentos y agonías que engendra un amor no correspondido, sus desventuras con Inaquia. Para ello, siguiendo el mismo procedimiento que hasta ahora hemos visto, se sirve, como un verdadero poeta elegíaco, de todos los tópicos habituales en Tibulo, Propercio y Ovidio ${ }^{27}$.

$\mathrm{Y}$ es que, aunque cada persona, cada poeta, siente el amor de una manera diferente, sin embargo todos siguen escrupulosamente las reglas de un género - el elegíaco - y además practican el mismo código descriptivo de lo erótico. En efecto, las poesías de Catulo tienen un carácter sincero y pasional; las de Tibulo son largas, de compleja estructura y temática diversa; las de Propercio son más breves, pero de estructura más firme, donde el elemento mitológico está siempre presente; Ovidio es más burlón e irónico; Horacio, en fin, aun sin ser un elegíaco, confiere al amor un papel relevante, destacando lo engañoso, efímero y perjudicial. Son, en suma, distintas concepciones poéticas del amor. Sin embargo, el código descriptivo de lo erótico que practican es el mismo.

De este modo, Horacio comienza a describir sus desgracias de amor con Inaquia mediante la expresión incompleta $\mathrm{Heu} \mathrm{me} \mathrm{(v.} \mathrm{7),} \mathrm{donde} \mathrm{el} \mathrm{predicativo}$ miserum está elíptico. Se trata, efectivamente, de la fórmula típica del schetliasmós (queja airada), un motivo amatorio tradicional en contextos eróticos. Suele aparecer siempre en boca de una mujer abandonada por el amante, como el de Ariadna contra Teseo (Catull. 64,132-142), el de Europa en Mosco (135 ss.) o el de Escila (Ov., Met. VIII 108 ss.) ${ }^{28}$.

La originalidad de Horacio consiste en presentarse a sí mismo como el amante agraviado y despreciado, que por su pasión desmedida y alocada siente haber hecho el ridículo por toda la ciudad y haber dado motivos de habladurías

27 Sobre los tópicos elegíacos y el lenguaje erótico en general, cf. G. Giangrande, «Los tópicos helenísticos en la elegía latina», EMERITA 42, 1974, pp. 1-36; E. Montero Cartelle, Aspectos léxicos y literarios del latín erótico (hasta el siglo I d. C.), Sevilla, 1992 (= Universidad de Santiago, 1973); R. Müller, Motiv-Katalog der römischen Elegie. Eine Untersuchung zur Poetik der Römer, Zurich, 1952.

28 Para el motivo, cf. N. P. Gross, Amatory Persuasion in Antiquity. Studies in Theory and Practice, Newark, 1985, pp. 69-123; R. O. A. M. Lyne, Ciris. A Poem Attributed to Vergil, Cambridge, 1978, ad Ciris 404-458. 
y cotilleos. El Venusino se duele por haber perdido el pudor y haber sido fabula. Se trata, igualmente, del motivo elegíaco del amante como centro de los chismes ${ }^{29}$. Horacio, además, no lanza reproches contra la persona amada, como era habitual en el schetliasmós, sino que con quien está indignado es consigo mismo. Se arrepiente con pudor y vergüenza (pudet, v.7; paenitet, v.8) de no haber sido, como preceptuaba Ovidio ${ }^{30}$, discreto en el amor. Ahora, cuando los posos de su antigua locura de amor están asentados en el fondo de la vasija del recuerdo, con la serenidad que le proporcionan los dos años transcurridos, el poeta se arrepiente de no haber sido recatado y de haber hecho públicos los signa amoris (síntomas de amor) que le delataban como enamorado:

\author{
...Conuiuiorum et paenitet \\ in quis amantem languor et silentium \\ arguit et latere petitus imo spiritus (vv. 8-10).
}

Horacio, uniendo los temas del convite y de los signa amoris, retoma la circustancia común en la poesía helenística del amante que, aun sin quererlo, revela, durante la celebración de un banquete y mediante su propio comportamiento, su condición de enamorado ${ }^{31}$. La palidez, la desidia, la flojedad son sintomas del amor ${ }^{32}$; el silencio revela la anulación mental que padece el enamorado, como cuando Catulo sintió el flechazo por Lesbia: lingua sed torpet (Catull. 51,9); los suspiros también dan fe del sufrimiento amoroso y suelen indicar tristeza por el amor no correspondido ${ }^{33}$.

Según parece, Horacio había perdido el amor de Inaquia por culpa de un rival adinerado que la habría cautivado, ofreciéndole bienes materiales que el poeta no estaba en disposición de regalar. El Venusino, como recalca en muchos de sus versos, no posee riquezas, sino que su única y gran fortuna es solamente su inspiración poética ${ }^{34}$. Es más, el rechazo de las riquezas es un tópico recurrente en el cancionero horaciano y, en general, en los de todos los poetas elegíacos. El amante, por antonomasia, es pobre; el rival, en cambio, es rico. Ello da lugar al motivo literario del dives amator, el amante rico, que arrebata al poeta su bien más preciado: la amada ${ }^{35}$.

${ }^{29}$ Cf. Tib. I 4,83; II 3,31 ss.; Prop. II 24,1; III 25,1-2; Ov., Am. III 1,21; Ars II 630.

${ }^{30}$ Ov., Ars II 601 ss.

${ }^{31}$ Cf. Call., Epigr. 43 Pf.; Asclepiad., Anth. Pal. XII 135, 3 ss.; y para la tradición epigramática latina, Val. Aedit., fr. 1,2; 4 Büch.

${ }_{32}$ Cf. R. Pichon, op. cit., p. 225.

${ }^{33}$ Cf. Tib. III 6,59-61; Prop. II 22,47 y R. Pichon, op. cit., p. 272.

${ }^{34}$ Cf. por ejemplo, Carm. II 16,37-40.

${ }^{35}$ Cf. por ejemplo, Tib. I 1 o II 3. 
En esta línea, Horacio, haciendo uso de un tema epigramático, contrapondrá el dinero del diues amator con el candidum ingenium (vv. 11-12) del enamorado pobre ${ }^{36}$. Y es que, tras haber manifestado su vergüenza por entregarse a un ciego amor, el Venusino expone en estilo directo las quejas que un día dirigió al mismo Petio. Son quejas que entran dentro de la tópica elegíaca y que suponen la propia resignación del amante por una batalla que considera ya perdida. Los motivos amatorios tradicionales abundan también en estos versos. En efecto, el poeta se ve traicionado por su amada y el único consuelo que le queda es sincerarse con su amigo Petio, quejarse y llorar ante él, pues Inaquia no hará ningún caso a estos llantos. Y para ello, para revelar a su amigo los secretos que alberga en su corazón, ha de buscar ayuda en el efecto benéfico del vino, que da fuerzas al amante incluso en los momentos más amargos ${ }^{37}$.

En su sinceramiento, el poeta confiesa a Petio que se encuentra indignado por las ofensas recibidas y que, ante esa indignación que le quema en su interior (inaestuet, v. 15), no encuentra alivio alguno. Y es que ese amor no correspondido ha ido horadando las entrañas del poeta hasta causarle una profunda herida. Es el tópico del uulnus amoris (v. 17) ${ }^{38}$. Visto, pues, que este amor sólo le ha producido desasosiego y malestar, Horacio termina su alocución a Petio asegurándole que, en lo sucesivo, dejará de competir con rivales que no sean de su misma talla, es decir, con esos diues amatores que con el poder de su dinero logran conseguir lo que se propongan: desinet imparibus certare... pudor (v. 18).

Una vez que el poeta había contado al amigo todos sus males amorosos, parece que éste le aconsejó que se calmara y que se marchara a casa para descansar (vv. 19-20). Sin embargo, Horacio, que debía de estar algo ebrio por los efectos del vino sincerador (cf. incerto pede, v. 20), se encamina, no sabemos si por equivocación o por propia decisión, hacia la puerta de su amada. Por tanto, en la parte final de la narración referida al pasado entra en juego uno de los tópicos amatorios más conspicuos de la poesía erótica latina: el motivo del paraclausithyron o llanto ante la puerta de la casa de la amada ${ }^{39}$.

\footnotetext{
${ }^{36}$ Cf. Anth. Pal. V 2; 29; 30; 31; IX 241; 411; 420; XI 416; XII 42; 44; 212; 214.

${ }^{37}$ Es un tópico alejandrino, cf. Asclepiad., A.P. XII 50; Meleagro, ibid. XII 119,5 ss. Call, Epigr. 43 Pf. Sobre el elemento del vino en Horacio, cf. A. P. Mckinlay, "The wine element in Horace», The Classical Journal 42, 1946-47, pp. 161-167 y 229-235; A. Richter, «La vertu du vin dans les odes d'Horace», Bulletin de la Faculté des lettres de Mulhouse III, 1970, pp. 3-10; M. Mañas Núñez, «El vino como recurso literario en las Odas de Horacio», en Actas del V Coloquio de Estudiantes de Filología Clásica, Valdepeñas, 1993, pp. 35-42,

38 Cf. R. Pichon, op. cit., p. 302 s. v. uulnera y Mckeown II, p. 48 ad Ov. Am. I 2,29-30.

${ }^{39}$ Cf. Pl., Curc. 145-155; Lucr. IV 1177-1179; Catull. 67; Hor., carm. I 25 y III 10; Tíb. I 2,1-34; Prop. I I6; Ov., Am. I 6. Véase F. O. Copley, Exclusus amator. A Study in
} 
De las muchas variantes que este motivo puede incorporar (frío, golpes a la puerta, guardia en la puerta, guirnaldas, llanto, rigor de la noche, besos a la puerta, silencio de la puerta, ofensas, regalos o poesías a la misma), el poeta alude a la hostilidad de la puerta (non amicos... postis, v. 21), que se interpone entre Inaquia y él y marca unas barreras imposibles de salvar; a la crueldad (limina dura, v. 22) de los umbrales, que no tienen compasión con una persona herida de amor; $y$ al hecho de dormir a la intemperie, pues parece que Horacio pasó la noche al aire libre, tumbado junto a la puerta, llorando sus penas y durmiendo su borrachera (quibus lumbos et infregi latus, v. 22).

Sin embargo, estas desagradables experiencias no han hecho escarmentar al poeta. Ya en los primeros versos nos anunciaba que se había vuelto a enamorar. Pero, tras esta rememoración de sus desgracias pasadas, esperábamos que, ante esta nueva pasión presente, mantuviera un espíritu más sereno y menos temperamental. Vemos, en cambio, que nada de esto ocurre. Horacio no escarmienta. En el momento actual, marcado fuertemente por el adverbio nunc (v. 23), el amor que siente por Licisco es equiparable al que experimentó por Inaquia, con la salvedad de que ahora se ha enamorado de un efebo. En definitiva, un amor pederástico que tiene visos de acabar como el de Inaquia. De hecho, parece que Horacio quisiera librarse de él, pero le es imposible, porque se encuentra prisionero y esclavo del propio amor que siente por el muchacho (me tenet, v. 24). Se trata del tópico del seruitium amoris ${ }^{40}$.

Horacio presenta al muchacho objeto de sus deseos como un joven altivo, arrogante y fanfarrón, que, seguramente, igual que el Ligurino de las odas IV 1 y IV 10, desprecia los requerimientos del poeta, pero que, gracias a su mollitie (v. 24), se vanagloria de poder vencer (uincere, v.24) a cualquier mujerzuela. En este caso, Horacio se sirve del léxico militar para expresar el poder cautivador del muchacho (gloriantis, v. 23; uincere, v. 24), siguiendo el conocido motivo de la militia amoris ${ }^{4 !}$.

El caso es que la pasión que experimenta Horacio por Licisco es tan intensa, el poeta se halla tan subyugado, prisionero y esclavo de ella, que vanos son todos los consejos de sus amigos (amicorum... libera consilia, v. 25), especialmente los de Petio, para que deje de atormentarse por ese joven. Es más, el

Latin Love Poetry, Madison, 1956; J. C. Yardley, «The elegiac Paraclausithyron», Eranos 76 , 1978, pp.19-34; W. J. Henderson, «The paraclasithyron motif in Horace's odes», Acta Classica 16, 1973, pp.51-67.

${ }^{40}$ Cf. F. O. Copley, «Servitium amoris in the Roman Elegists», TAPhA 78, 1947, pp. 285-300; R. O. A. M. Lyne, «Servitium amoris», CQ. 29, 1979, pp. 117-130; A. Ramírez de Verger, «El amor como seruitium en Tibulo», en Simposio Tibuliano, Murcia, 1985 , pp. 371-377.

41 Cf. P. Murgatroyd, "Militia amoris and the Roman Elegists», Latomus 34, 1975, pp. 59-79. 
mismo Horacio nos dice que ni siquiera las «graves ofensas» (contumeliae graues, v. 26) que el joven pudiera infligirle ${ }^{42}$ podrán hacerle cejar en sus intentos de conquistarlo y gozar con él los placeres de Venus. Estas contumeliae que Horacio podría sufrir por parte de Licisco, si es que no las ha probado ya, no son otras que las que Inaquia le procuró y cuya relación ha reunido en la parte central del epodo.

El único remedium amoris que Horacio encuentra para desprenderse de esta ardorosa pasión que le tiene esclavizado es alius ardor. Sólo es posible olvidarse de un amor mediante otro amor, explotando así un tema muy común en la elegía ${ }^{43}$.

El poema finaliza, pues, de la misma manera que comenzó. Efectivamente, los primeros versos nos presentaban al poeta víctima de un deseo interior incontrolable, que le hacía inflamarse por cualquier mollis puer aut puella (v. 4). A su vez, estos últimos versos nos presentan al poeta intentando librarse del amor por un efebo y, para ello, sólo confía en que le sobrevenga otra ardorosa pasión aut puellae candidael aut teretis pueri (vv. 27-28). Creemos, por tanto, que temáticamente se puede hablar de una composición anular:

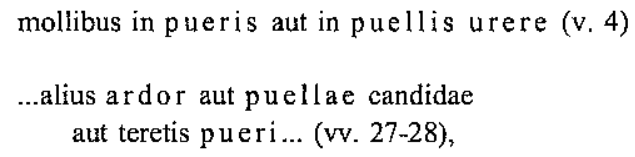

con la repetición del motivo de la flamma amoris y de las palabras claves puer y puella. Pero creemos que también desde el punto de vista estructural se puede hablar de Ringkomposition:

- Presente (vv. 1-6)

- Pasado (vv. 7-22)

- Presente (vv. 23-28).

Concluyendo, Horacio sabe distinguir bien entre amor y deseo sexual. Él, al usar el verbo tenere (v. 24), caracteriza sus sentimientos por Licisco como

\footnotetext{
42 Siguiendo a Porfirión, entendemos que estas contumeliae graues del v. 26 le vienen non iam amicorum, sed ipsius pueri, qui amatur, cf. Porfirión, Commentum in Horatium Flaccum, Recensuit A. Holder, Hildesheim, 1967, p. 206 ad loc. Comentaristas modernos, como por ejemplo E. Romano, op. cit., entienden que el genitivo amicorum acompaña tanto a los consilia como a las contumeliae.

43 Cf. A.P. V 121, 5-6; Teoc., Ibid. XI, 76; Verg., Ecl. II,74; Hor., Epod. XV, 14; Prop. II 3,45 ss.; 5, 5-6; 17,17 ss.; Tib., I 9,79 ss.; Ov., Rem. 441; 462; Cf. G. Laguna Mariscal, «Estructura y significación de la Oda IV 11 de Horacio», Anuario de Estudios Filológicos 14, 1991, pp. 269-281, especialmente p. 277.
} 
una afección amorosa de larga duración. En cambio, en otras ocasiones, lo que siente por un joven esclavo, masculino o femenino, es sólo puro deseo sexual, como cuando hace la vulgar observación

...tument tibi cum inguina, num si

ancilla aut uerna est praesto puer, impetus in quem

continuo fiat, malis tentigine rumpi? (Serm. I 2,116-118).

Horacio es partidario de satisfacer sus deseos sexuales cuando se presenten. Tiende a la regla epicúrea de preferir simples divertimentos sexuales que le proporcionen gozo físico y rechazar toda afección amorosa por la perturbación física y psíquica que conlleva. Su razón e ideales epicúreos le hacen asegurar en primera persona parabilem amo uenerem facilemque (Serm. I 2,119).

Sin embargo, en las composiciones líricas intimistas, como este epodo que comentamos, la vena poética vence a la filosófica. Horacio es más poeta que filósofo, pues ni amicorum consilia ni contumeliae graues (v. 25) pueden librarle de su amor por Licisco, que es tan violento y vergonzoso como el que tuvo por Inaquia.

La pregunta ineludible e irresoluble que nos hacemos es la siguiente: ¿Qué relación hay entre la vida y la poesía de Horacio? ¿Qué hay de verdad autobiográfica y qué de convención literaria en su obra? En relación a las Odas IV, I y IV,10, también de tema pederástico, ya dijimos en su momento que, en medio de tal despliege de tópicos, podía haber algún resquicio autobiográfico. Se trataba entonces de un poeta cincuentón que contaba cómo un joven le había rechazado por su vejez. Ahí creímos ver las dolidas entrañas de un hombre verdaderamente atormentado, metido a amante, pero ya decrépito y decadente; de un poeta que se servía de un amplio mosaico de temas y formas para narrar su impotencia vital. Pero el caso de este epodo es diferente. Se trata ahora de un poema escrito casi treinta años antes y de un poeta de poco más de veinte, de sensibilidad viva e irascible, enojado consigo mismo y descontento con todo, que lee una y otra vez las obras de Eupolis, Aristófanes, Arquíloco y Lucilio. Que escribe Sátiras y Epodos por la necesidad que siente de ironizar y de burlarse de las cosas y de las personas. Creemos, en efecto, que este epodo XI es un mero ejercicio literario, pues, tras ese código descriptivo de lo erótico tan tipificado, no logramos atisbar nada de la humanidad que rezumarán las dos odas mencionadas. En este poema todo parece artificial ${ }^{44}$.

\footnotetext{
44 Cf. E. Fraenkel, Horace, p. 67.
} 
En fin, tal vez carezca de importancia saber si esta historia de amor, como tantas otras, fue vivida o inventada, pues, como dice Alvar en su libro sobre la poesía de amor en Roma, «el viaje al interior del corazón del hombre es una aventura que se goza a solas con la única fuerza de la imaginación (o ¿acaso no son las caricias más bellas, las soñadas?)» ${ }^{45}$.

MANUel MAÑAS NúÑEZ

45 A. Alvar Ezquerra, Poesía de amor en Roma. Catulo, Tibulo, Ligdamo, Sulpicia, Propercio, Madrid, 1993, p. 64. 